\title{
CHUVA DE SEMENTES EM UMA FLORESTA DE GALERIA NO PARQUE DO BACABA, EM NOVA XAVANTINA, MATO GROSSO, BRASIL ${ }^{1}$
}

\begin{abstract}
Maria do Carmo Correa Lagos² e Beatriz Schwantes Marimon ${ }^{3}$
RESUMO - O estudo foi realizado na floresta de galeria do Córrego Bacaba, no Parque Municipal do Bacaba (14²3'12,2S e 52²1'36,7"W), em Nova Xavantina, MT. A dispersão de sementes foi analisada e comparada entre três porções da floresta (alto, meio e baixo), distantes cerca de 200 m entre si, em um gradiente topográfico. Foram distribuídos, aleatoriamente, 20 coletores circulares de $0,3 \mathrm{~m}^{2}$ em cada porção de floresta, sendo as coletas de sementes realizadas quinzenalmente, entre junho de 2007 e maio de 2008. O material foi submetido à secagem em estufa até peso constante e as sementes, separadas em duas categorias, baseando-se na presença de estruturas de voo (V) e na ausência dessas estruturas (NV). O número de morfoespécies e de sementes e a biomassa foram comparados entre as porções de floresta e entre os períodos seco e chuvoso. Coletaram-se 20.965 sementes em 24 quinzenas, sendo 777 do tipo V e 20.188 do tipo NV. Na porção do alto ocorreram 52 morfoespécies de sementes, no meio 55 e no baixo 49. A diversidade de morfoespécies de sementes foi inferior à diversidade de espécies de plantas lenhosas na mesma área. Considerando o padrão sazonal de dispersão de sementes, tanto para as V (número, morfoespécies e biomassa) quanto para as NV (biomassa), recomenda-se um controle no fluxo de visitantes no Parque do Bacaba, especialmente nos meses de pico de dispersão de sementes, no final do período seco e início do chuvoso (setembro-dezembro). Medidas de excursionismo de mínimo impacto poderão trazer benefícios para o estabelecimento de sementes e plântulas e garantir a sustentabilidade da floresta.
\end{abstract}

Palavras-chave: Sazonalidade, Diásporos e Conservação.

\section{SEED RAIN IN A GALLERY FOREST IN THE BACABA PARK, NOVA XAVANTINA, MATO GROSSO STATE, BRAZIL}

\begin{abstract}
The study was carried out in the gallery forest of the Bacaba stream, Municipal Bacaba Park

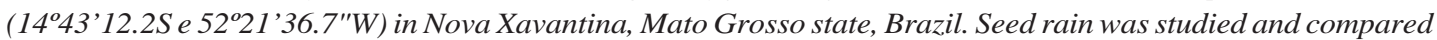
among three forest sections (upper, middle and lower), $200 \mathrm{~m}$ away from each other, running downstream and differing in slope. Twenty circular seed-traps $\left(0.3 \mathrm{~m}^{2}\right)$ were randomically distributed at each forest section and monitored from June 2007 to May 2008. Seeds were dried until constant weight, and classified in two categories, based on the presence of flight structures ( $V$ ) and the absence of these structures (NV). Number of morpho-species, seeds and biomass were compared at the forest sections through the dry and rainy periods. It was collected 20,965 seeds over 24 fortnights, being 777 seeds type V and 20,188 seeds type NV. In the upper section, 52 morpho-species of seeds were recorded in the middle 55 and in the lower 49. The morphospecies diversity of seeds was lower than the diversity of the woody species in the same area. Regarding the seasonal pattern for seed rain, for $V$ (number, morpho-species and biomass) and for $N V$ seeds (biomass) as well, the control of visitors in the Bacaba Park especially in the dispersion peak of seeds at the end of dry period and the beginning of the rains (September-December) is recommended. Tour of minimum impact may benefit the establishment of seeds and seedlings and ensure sustainability of the forest.
\end{abstract}

Keywords: Seasonality, Diaspores and Conservation.

\footnotetext{
${ }^{1}$ Recebido em 08.07.2009 e aceito para publicação em 29.03.2012

${ }^{2}$ Universidade do Estado de Mato Grosso, Campus de Cáceres, Programa de Pós-graduação em Ciências Ambientais.

${ }^{3}$ Universidade do Estado de Mato Grosso, Campus Universitário de Nova Xavantina, Departamento de Ciências Biológicas. E-mail: <biamarimon@hotmail.com>.
} 


\section{INTRODUÇÃO}

As florestas de galeria constituem uma fitofisionomia muito particular no contexto das florestas brasileiras, principalmente em relação à composição florística e às condições ambientais, as quais podem variar muito em áreas relativamente pequenas (OLIVEIRA-FILHO, 1989). O referido autor ressaltou ainda que as variações das condições hídricas do solo, relacionadas à topografia, representam o principal fator que determina a elevada heterogeneidade das florestas de galeria, mas outras variáveis ambientais, como a textura e a fertilidade do solo, também podem ser relevantes.

A heterogeneidade florística e ambiental das florestas de galeria ressaltam a fragilidade dessa vegetação, que exige a proteção de áreas amplas para que a conservação in situ de seu patrimônio genético seja satisfatória (OLIVEIRA-FILHO, 1989). Nesse contexto, a chuva de sementes é fator importante, pois constitui o processo-chave para garantir o sucesso reprodutivo das espécies na comunidade vegetal (MARTINS et al., 2007).

Define-se “chuva de sementes" o conjunto de sementes que cai sobre o solo (GARCIA, 2007), as quais podem ser originadas de plantas que estão produzindo frutos localmente como daquelas de áreas adjacentes, cujas sementes são transportadas por um agente dispersor (ALVAREZ-BUYLLA; MARTÍNEZRAMOS, 1990). Segundo Swaine e Whitmore (1988), os padrões da história de vida das espécies tropicais podem ser moldados pelas características das suas sementes, determinando onde e como o estabelecimento e a germinação podem ocorrer.

Em ecossistemas tropicais, a variação sazonal nos ritmos de frutificação pode contribuir com alterações na quantidade de sementes, assim como nas espécies encontradas no banco de sementes ao longo do ano e entre anos (GROMBONE-GUARATINI, 1999). Dessa forma, a dispersão espacial das sementes pode definir o modelo do padrão de recrutamento e regeneração de uma população (LOISELLE et al., 1996).

Em uma floresta, a chuva de sementes representa sua comunidade potencial, visto que esta pode ser invadida por propágulos externos ou originados localmente (ARAÚJO et al., 2004), e a sucessão depende do potencial de dispersão de suas espécies (GROMBONE-GUARATINI, 1999). Estudos sobre a chuva de sementes em florestas ripárias indicaram que podem ocorrer diferenças entre trechos de uma mesma floresta e semelhanças entre diferentes períodos do ano (ARAÚJO et al., 2004; PIVELLO et al., 2006). Além disso, alguns estudos em florestas tropicais brasileiras incluíram a caracterização da composição florística, da densidade e frequência, do padrão espacial e sazonalidade climática da chuva de sementes (PENHALBER; MANTOVANI, 1997; GROMBONE-GUARATINI; RODRIGUES, 2002; MELO et al., 2006; MARIMON; FELFILI, 2006; CAMPOS et al., 2009), contribuindo com informações para garantir a conservação e manejo dessas florestas.

O objetivo deste estudo foi investigar a variação temporal e espacial na chuva de sementes, durante um ano, em três porções da floresta de galeria do Parque do Bacaba, em Nova Xavantina, MT, permitindo a avaliação do potencial de regeneração da comunidade e contribuindo para o plano de manejo do Parque.

\section{MATERIAL E MÉTODOS}

O estudo foi realizado em três porções da floresta de galeria do Córrego Bacaba, no Parque Municipal do Bacaba (1443’12,2" S e 52²1’36,7" W), no Município de Nova Xavantina, região Nordeste do Estado de Mato Grosso. O parque do Bacaba ocupa uma área de aproximadamente 500 ha, e a floresta de galeria localiza-se na divisa Oeste do parque, ocupa cerca de 10 ha e possui importância estratégica, pois protege o córrego que abastece, sem tratamento prévio, um bairro do município (MARIMON et al., 2001; 2002; 2003; 2010).

As porções de floresta que foram estudadas, doravante denominadas alto, meio e baixo, distam cerca de $200 \mathrm{~m}$ entre si em um gradiente topográfico (MARIMON et al., 2010). A porção do alto, com declividade média de $42 \%$, caracteriza-se pela presença de afloramentos rochosos de quartzito e ocorrência de enchentes sazonais com drenagem rápida. Na porção do meio, com declividade média de 32\%, também há afloramentos rochosos e o lençol freático aflora no período chuvoso nas partes de menor declive. Quanto à porção do baixo, a declividade média é de 5\%, as rochas estão ausentes e a drenagem do solo é deficiente, provocando seu alagamento durante a maior parte do ano (MARIMON et al., 2003, 2010).

Em 1999 foram demarcadas 47 parcelas permanentes de 10 x 10 m em cada porção de floresta (total de $14.100 \mathrm{~m}^{2}$ ), visando a uma caracterização florística e estrutural da vegetação. As parcelas foram posicionadas contínua 
e sistematicamente, perpendiculares ao córrego e cobrindo toda a área coberta pela floresta até a borda, no encontro com o Cerrado stricto sensu (MARIMON et al., 2001, 2002, 2003).

Para a coleta dos dados de chuva de sementes (junho/2007 a maio/2008) foram utilizados 60 coletores circulares com diâmetro de $62 \mathrm{~cm}\left(0,3 \mathrm{~m}^{2}\right)$, confeccionados com vergalhões de ferro e com uma bolsa piramidal invertida formada por uma rede de tela plástica com malha de $2 \mathrm{~mm}$. Em cada porção de floresta (alto, meio e baixo) foram instalados, aleatoriamente, 20 coletores dispostos no centro das parcelas sorteadas.

As sementes de cada coletor foram recolhidas quinzenalmente e acondicionadas em sacos de papel devidamente identificados; em seguida, foram colocadas para secar em estufa $\left(70^{\circ} \mathrm{C}\right)$ até peso constante. Os frutos maduros (deiscentes ou indeiscentes) que caíram nas armadilhas também tiveram as sementes separadas, contadas e secadas em estufa. Para efeito de pesagem, os frutos foram considerados íntegros, incluindo-se as sementes, e antes da pesagem destas efetuou-se a retirada de todas as estruturas ou partes associadas ao fruto. Posteriormente, as sementes foram identificadas (morfoespécies) e separadas em duas categorias, baseando-se na presença de estruturas de voo (V) na semente ou no diásporo e na ausência dessas estruturas (NV). A abundância temporal das sementes foi expressa a partir do número de morfoespécies, número e biomassa das sementes (gramas), calculadas por período de coleta por área $\left(\mathrm{m}^{2}\right)$. Cada época de coleta (quinzenal) foi classificada como pertencente ao período chuvoso (novembro a abril) ou período seco (maio a outubro). Os dados de precipitação pluviométrica ( $\mathrm{mm}$ ) foram coletados na Estação Meteorológica de Nova Xavantina (Ministério da Agricultura, Pecuária e Abastecimento - MAPA, $9^{\circ}$ Distrito de Meteorologia), localizada na Universidade do Estado de Mato Grosso, Campus de Nova Xavantina, distante cerca de $2 \mathrm{~km}$, em linha reta, da área de estudo.

Para os dados do número de sementes e da riqueza de morfoespécies da chuva de sementes, não houve distribuição normal e nem variâncias homogêneas (teste de Kolmogorov-Smirnov e teste de Bartlett). Nesse caso, foi utilizado o teste não paramétrico de KruskalWallis para comparar o número de sementes (NSV = número de sementes com estruturas de voo e NSNV = número de sementes sem estruturas de voo, ou não voo), o número de morfoespécies (NEV e NENV) e a biomassa de sementes (BV e BNV) entre as três porções de floresta. O teste não paramétrico de Mann-Whitney foi utilizado para comparar NSV, NSNV, NEV, NENV, $\mathrm{BV}$ e BNV entre os períodos seco e chuvoso, para cada porção de floresta e para as três porções em conjunto. As análises estatísticas foram feitas a partir do software SYSTAT 7.0 (SPSS, 1997).

Para avaliar a diversidade de morfoespécies de sementes coletadas nas três porções de floresta foi utilizado o índice de diversidade de espécies de ShannonWiener (H'), e para avaliar a equabilidade foi utilizado o índice de Pielou (J) (MAGURRAN, 1988; LUDWIG; REYNOLDS, 1988). Para comparar os resultados de H' obtidos para a chuva de sementes com os resultados do índice de diversidade das espécies de plantas (árvores, arbustos, lianas e palmeiras) determinados nas mesmas parcelas e porções de floresta por Miguel e Marimon (2008), foi aplicado o teste $t$ de Hutcheson (ZAR, 1999).

\section{RESULTADOS}

Nas 60 armadilhas distribuídas nas três porções da floresta de galeria do Córrego Bacaba, foram coletadas 20.965 sementes no período de 24 quinzenas, sendo 777 sementes que tinham estruturas de voo (V) e 20.188 sem essas estruturas (NV). Considerando-se todas as sementes coletadas nas três porções de floresta, 96\% são do tipo NV e 4\% do tipo V. Entre as sementes NV, $5 \%$ se concentraram na porção do alto, $74 \%$ no meio e $21 \%$ no baixo; das sementes V, $43 \%$ se concentraram no alto, $7 \%$ no meio e $50 \%$ no baixo.

A proporção do número total de sementes foi de 1:3:11 nas porções do alto, baixo e meio e a proporção da biomassa total de sementes, de 1:2:2, respectivamente para o meio, alto e baixo. Considerando-se apenas as sementes com estruturas de voo (V), a proporção foi de 1:6:7, no meio, alto e baixo, sendo para o número de sementes sem estruturas de voo (NSNV) 1:4:14 no alto, baixo e meio, respectivamente.

Comparando o número de sementes com estruturas de voo (NSV), o número de morfoespécies (NEV) e a biomassa (BV) distribuídos em 24 quinzenas nas três porções de floresta, verificou-se que não houve diferença entre as porções $(p>0,08)$.

O NSV e a BV no período estudado foram marcadamente sazonais para as porções da floresta consideradas em conjunto (períodos seco e chuvoso

Revista Árvore, Viçosa-MG, v.36, n.2, p.311-320, 2012 
- NSV: $\left.\chi^{2}=9,59, p=0,002 ; \mathrm{BV}: \chi^{2}=9,13, p=0,003\right)$, com maior produção no final do período seco e início do chuvoso (Figura 1A). Analisando o NSV para cada porção de floresta separadamente, foi registrada diferença sazonal nas porções do alto $\left(\chi^{2}=4,33, p=0,03\right)$ e do baixo $\left(\chi^{2}=6,82, p=0,009\right)$, sendo os maiores valores registrados no início do período chuvoso (Figura 1A). Considerando o NEV, também foram registrados maiores valores no final do período seco e início do chuvoso, tanto para a floresta $\left(\chi^{2}=8,38, p=0,004\right)$ quanto para as porções analisadas separadamente (alto: $\chi^{2}=4,76$, $p=0,03$ e baixo: $\left.\chi^{2}=4,22, p=0,04\right)$.

Na porção do alto ocorreu um pico na queda de sementes (NSNV) no final do período chuvoso (Figura 1B). Na porção do meio foi registrada grande (> 1.500) queda de sementes no mês de junho (período seco), a qual, durante o ano, foi uniforme e muito baixa, enquanto na porção do baixo ocorreram vários picos durante o período chuvoso e o mais elevado no final do período seco (Figura 1B).

Os picos de biomassa de sementes com estruturas de voo (BV) na porção do baixo ocorreram no final do período seco e início do chuvoso (Figura 1C), sendo superior nesse período $\left(\chi^{2}=5,91, p=0,01\right)$. Entretanto, nas porções do alto e do meio para a BV não se constatou diferença entre os dois períodos $(p>0,1)$.

Comparando o número de sementes (NSNV), o número de morfoespécies (NENV) e a biomassa de sementes sem estruturas de voo (BNV) distribuídos em 24 quinzenas nas três porções de floresta, verificou-se que não houve diferença entre as porções $(p>0,1)$. Para o NSNV e o NENV, analisados conjuntamente para as porções amostradas, não foram registradas diferenças entre os períodos seco e chuvoso ( $p>0,2)$, sendo apenas a BNV superior no período chuvoso $\left(\chi^{2}=5,81, p=0,016\right.$; Figura 1D). Analisando cada porção de floresta separadamente, verificou-se que o NSNV e o NENV também não diferiram entre os períodos seco e chuvoso $(p>0,05)$. Apenas na porção do baixo constatou-se maior BNV no período chuvoso $\left(\chi^{2}=4,08, p=0,04\right)$, com picos nos meses de outubro, dezembro e janeiro (Figura 1D).

Na floresta de galeria do Córrego Bacaba foram registradas 91 morfoespécies de sementes, sendo 13 com a presença de estruturas de voo e 78 sem essas estruturas. Na porção do alto ocorreram 52 morfoespécies, no meio 55 e no baixo 49. Os valores de diversidade ( $\mathrm{H}^{\prime}$ ) de morfoespécies de sementes,
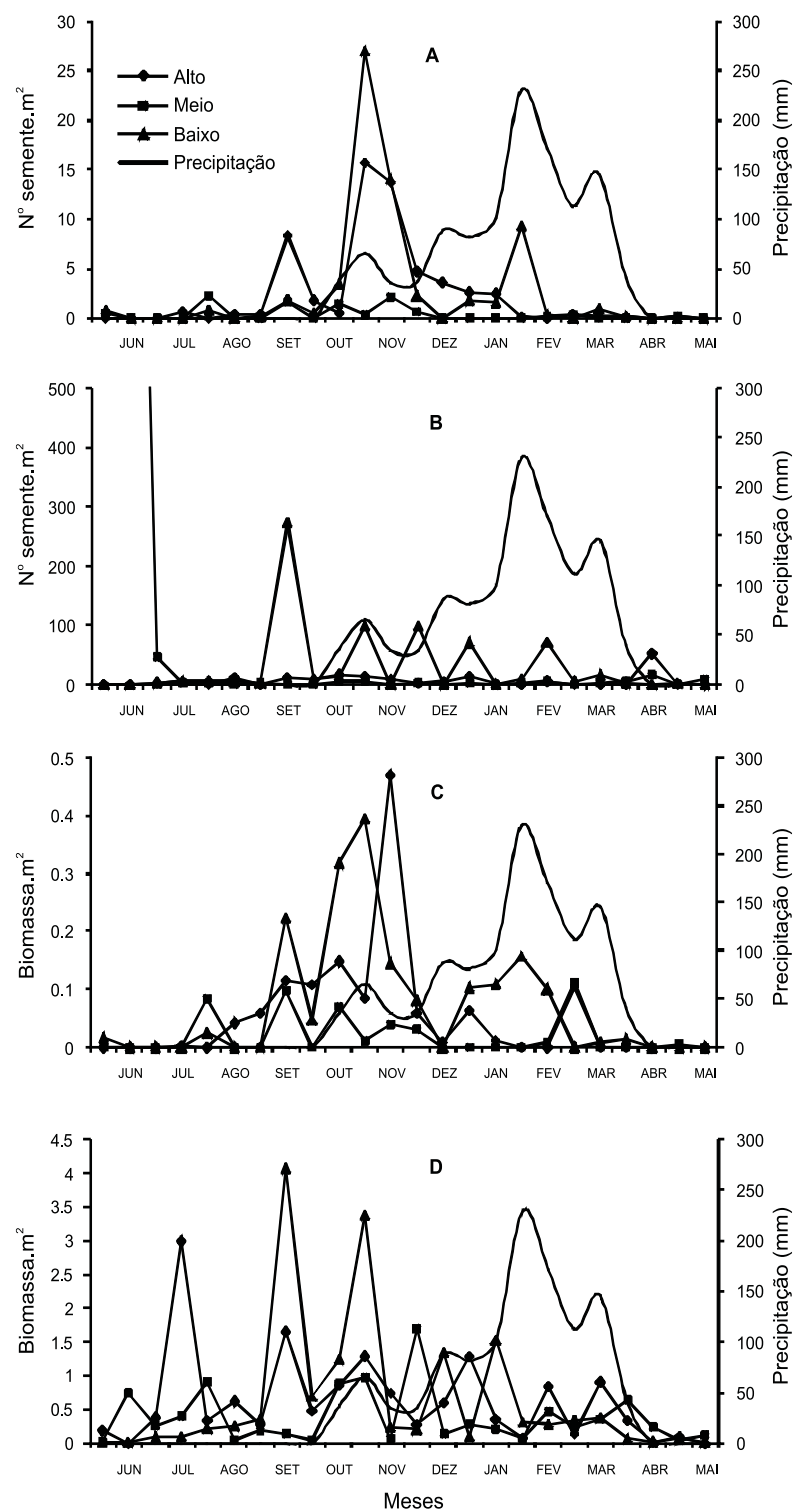

Figura 1 - Chuva de sementes com estruturas de voo (A $\mathrm{n}^{\text {o }}$ sementes. $\mathrm{m}^{-2}$ e C - biomassa, g. $\left.\mathrm{m}^{-2}\right)$ e sem essas estruturas (B - $\mathrm{n}^{\mathrm{o}}$ sementes. $\mathrm{m}^{-2}$ e D - biomassa, g. $\left.\mathrm{m}^{-2}\right)$ e curva de precipitação $(\mathrm{mm})$ de junho de 2007 a maio de 2008, em três porções (alto, meio e baixo) da floresta de galeria do Parque do Bacaba, Nova Xavantina, MT.

Figure 1 - Seed rain (Number, seeds. $m^{-2}$ and biomass, g. $\mathrm{m}^{-2}$ ) with flight structures (A and C) and without these structures ( $B$ and $D$ ) and precipitation ( $\mathrm{mm}$ ) from June 2007 to may 2008, in three sections (upper, middle and lower) in the gallery forest of the Bacaba Park, Nova Xavantina, Mato Grosso state. 
calculados separada e conjuntamente para as três porções da floresta do Córrego Bacaba, variaram de 3,14 a 3,62 nats ind.$^{-1} \mathrm{e}$ foram inferiores aos valores registrados para as espécies lenhosas (Tabela 1).

\section{DISCUSSÃO}

No presente estudo, o número total de sementes dispersas foi similar aos valores registrados em fragmentos de floresta atlântica e em florestas em sucessão (MARTINI, 2002; ARAÚJO, 2002; PIVELLO et al., 2006), foi cerca de duas vezes superior ao encontrado em uma floresta de restinga em São Paulo (SILVA, 2006) e quatro vezes superior ao valor registrado em florestas estacionais semideciduais de Mato Grosso (MARIMON; FELFILI, 2006). Isso confirma um padrão esperado em florestas de galeria do Brasil Central, visto que estas abrigam 33\% do número total de espécies conhecidas no bioma Cerrado (FELFILI et al., 2001; MIGUEL; MARIMON, 2008; RIBEIRO; WALTER, 2008).

A maior proporção do número total de sementes dispersas (V e NV) foi registrada na porção do meio da floresta estudada. Considerando que Marimon et al. (2010) registraram maiores concentrações de macro e micronutrientes no solo dessa porção, quando comparada com as do alto e do baixo, sugere-se que a maior fertilidade pode estar favorecendo a maior produção de sementes no meio em relação às demais porções avaliadas.
O maior porcentual de sementes com estruturas de voo ausentes (NSNV) na porção do meio da floresta estudada também pode estar relacionado à maior riqueza de espécies zoocóricas registrada nessa porção (MIGUEL; MARIMON, 2008). Entre as espécies de maior importância ecológica na porção do meio estão Hymenaea courbaril, Tetragastris altissima, Pouteria torta, Ephedranthus parviflorus e Vitex polygama (MARIMON et al., 2002), todas zoocóricas e com frutos amplamente consumidos pela fauna silvestre (POTT; POTT, 1994; IBGE, 2002; MIGUEL; MARIMON, 2008). Na porção do baixo foi registrado o segundo maior percentual de NSNV, na mesma área onde Mauritia flexuosa foi a espécie de maior importância ecológica (MARIMON et al., 2002, 2003, 2010), cujos frutos e sementes também são grandes $(>5 \mathrm{~cm})$, abundantes e importantes para a alimentação da fauna (POTT; POTT, 1994).

O maior percentual de sementes com estruturas de voo (NSV) foi observado na porção do baixo, podendo estar relacionado à maior densidade de espécies pioneiras registrada por Miguel e Marimon (2008) nessa mesma porção de floresta, confirmando o padrão observado por Liebsch e Acra (2007) de que espécies pioneiras geralmente têm dispersão anemocórica e estão associadas a áreas mais abertas. Entretanto, considerando-se as três porções de floresta amostradas, registrou-se reduzida densidade de

Tabela 1 - Índice de diversidade de espécies de Shannon-Wiener (H’), equabilidade de Pielou (J) e número de espécies (N) de cada porção e das três porções em conjunto, calculados em relação às morfoespécies de sementes e às espécies de árvores, arbustos, palmeiras e lianas da floresta de galeria do Córrego Bacaba, em Nova Xavantina, MT. Comparações entre os valores de $H^{\prime}$ foram efetuadas a partir do teste $t$ de Hutcheson, sendo valores de $p<0,05$ estatisticamente significativos. DAP = diâmetro ao nível do peito.

Table 1 - Shannon-Wiener's species diversity index ( $\left.H^{\prime}\right)$, Pielou's evenness index $(J)$ and number of species $(N)$ in three forest sections and total area sampled, calculated for seed morpho-species and species of trees, shrubs, palm trees and lianas of the Bacaba gallery forest, Nova Xavantina, Mato Grosso state. Comparisons between H' values were made from the Hutcheson t-test, and p-values $<0.05$ are statistically significant. DAP = diameter at breast height.

\begin{tabular}{|c|c|c|c|c|c|c|c|c|c|c|c|c|}
\hline \multirow{2}{*}{ Grupos de espécies } & \multicolumn{3}{|c|}{ Alto } & \multicolumn{3}{|c|}{ Meio } & \multicolumn{3}{|c|}{ Baixo } & \multicolumn{3}{|c|}{ Floresta } \\
\hline & $\mathrm{H}^{\prime}$ & $\mathrm{J}$ & $\mathrm{N}$ & $\mathrm{H}^{\prime}$ & $\mathrm{J}$ & $\mathrm{N}$ & $\mathrm{H}^{\prime}$ & $\mathrm{J}$ & $\mathrm{N}$ & $\mathrm{H}^{\prime}$ & $\mathrm{J}$ & $\mathrm{N}$ \\
\hline Sementes & 3,14 & 0,79 & 52 & 3,53 & 0,88 & 55 & 3,18 & 0,82 & 49 & 3,62 & 0,80 & 91 \\
\hline $\begin{array}{l}\text { Árvores, arbustos, palmeiras } \\
\text { e lianas }(\mathrm{DAP} \geq 5 \mathrm{~cm})^{1}\end{array}$ & 3,66 & 0,84 & 77 & 4,02 & 0,90 & 88 & 3,45 & 0,81 & 71 & 4,10 & 0,83 & 135 \\
\hline$t$ & 5,42 & & & 5,51 & & & 2,94 & & & 8,25 & & \\
\hline$p$ & $<0,001$ & & & $<0,001$ & & & $<0,01$ & & & $<0,001$ & & \\
\hline
\end{tabular}

${ }^{1}$ Miguel e Marimon (2008). 
sementes com estruturas de voo (4\%), o que pode refletir uma condição de fechamento após distúrbio (MIGUEL; MARIMON, 2008).

A proporção da biomassa total de sementes diferiu da proporção do número de sementes entre as porções de floresta estudadas. Nesse caso, sugere-se que a frequência de espécies que produzem sementes de grande porte nas porções do alto (Diospyros guianensis) e do baixo (Mauritia flexuosa) possa ser o fator determinante para a maior proporção de biomassa de sementes em relação à porção do meio. Marimon e Felfili (2006) também encontraram diferenças entre a proporção da biomassa e do número de sementes em florestas na região Leste de Mato Grosso e relacionaram o fato à produção maciça de frutos de algumas espécies. Nesse caso, sementes grandes aumentam o vigor das plântulas, e maior investimento parental resultaria em maior probabilidade de sobrevivência, aumentando as chances de serem abundantemente representadas na comunidade (FOSTER e JANSON, 1985; MARTÍNEZ-RAMOS; SOTO-CASTRO, 1993), tal como ocorreu com as espécies de maior importância ecológica anteriormente citadas, para as porções do alto e do baixo na floresta estudada.

O número de morfoespécies de sementes na floresta de galeria do Córrego Bacaba foi elevado em comparação com outros estudos que avaliaram a chuva de sementes em florestas nas regiões Sudeste e Centro-Oeste (ARAÚJO, 2002; PIVELLO et al., 2006; MARIMON; FELFILI, 2006). Além disso, a riqueza de espécies com sementes destituídas de estruturas de voo na área estudada reafirma o importante papel das florestas de galeria na disponibilização de alimento para a fauna silvestre (SCHIAVINI et al., 2001). Nesse caso, os dispersores de sementes são fundamentais tanto para o sucesso individual das plantas quanto para a estrutura e dinâmica das populações e comunidades vegetais (PHILLIPS, 1997).

O fato de não ter sido registrada diferença significativa entre as porções de floresta para o número, morfoespécies e biomassa de sementes com (V) e sem (NV) estruturas de voo pode estar relacionado à proximidade geográfica das porções. Além disso, o fato de não haver diferença nas características mencionadas entre as três porções de floresta pode representar importante característica na conservação dessa comunidade, pois, apesar da marcante heterogeneidade ambiental das porções estudadas (MARIMON et al., 2003, 2010), o padrão de produção de sementes dispersas não diferiu entre elas.

O NSV, o NEV e a BV no período estudado foi, entretanto, marcadamente sazonal, com picos no final do período seco e início do chuvoso. Nesse caso, as espécies anemocóricas têm dispersão favorecida no período seco ou de transição entre seco e chuvoso, pois são pequenas, leves, facilmente derrubadas com a chuva e com maior deciduidade das espécies, o que, associado à reduzida precipitação, pode garantir maior eficiência na dispersão (VAN DER PIJL, 1972; MORELLATO, 1995). Assim, a sazonalidade registrada neste estudo para as sementes com estruturas de voo está de acordo com outros estudos realizados em florestas neotropicais, nas quais sementes dispersas pelo vento predominam no período seco e início do chuvoso (FOSTER; JANSON, 1985; GROMBONEGUARATINI, 1999; GROMBONE-GUARATINI; RODRIGUES, 2002; MARIMON; FELFILI, 2006; GARCIA, 2007). Considerando o padrão sazonal de dispersão de sementes, identificado neste estudo, um controle no fluxo de visitantes no Parque do Bacaba, especialmente no pico de dispersão de sementes, poderá reduzir o impacto sobre os diásporos depositados sobre o solo.

Os picos da biomassa das sementes sem estruturas de voo (NV) foram registrados no período chuvoso, cujo padrão pode ser fundamental para acelerar a dinâmica de sucessão em uma floresta de galeria (PINTO et al., 2005) e está de acordo com o que foi observado por Jackson (1981), Foster e Janson (1985), Holl (1999) e Grombone-Guaratini e Rodrigues (2002) em florestas tropicais, onde os picos de ocorrência de sementes que não são dispersas pelo vento o são no início e no decorrer do período chuvoso.

Nas porções de floresta avaliadas nesta pesquisa também foram registrados pequenos picos no número e biomassa de sementes em diversos meses durante o ano. Marimon e Felfili (2006) sugeriram que a ocorrência de picos frequentes de queda de sementes no decorrer do ano está associada à maior diversidade de espécies, como foi o caso da floresta estudada, na qual se constataram elevada riqueza e diversidade de espécies. Nesse caso, os picos que ocorreram no final do período seco e início do chuvoso podem garantir e ampliar a germinação de sementes, visto que a dispersão 
acontece em época favorável ao estabelecimento e crescimento de plântulas, aumentando o sucesso reprodutivo das espécies (MARQUES, 2002) e garantindo a manutenção da diversidade de espécies na comunidade.

A diferença observada na produção de biomassa (BNV) entre os períodos seco e chuvoso na porção do baixo pode ser explicada pela espécie de maior importância ecológica dessa porção, Mauritia flexuosa, cujas sementes são de grande porte e biomassa, que normalmente são dispersas entre setembro e novembro (MARIMON et al., 2003; MIGUEL; MARIMON, 2008), confirmando a diferença sazonal registrada nessa porção. De forma semelhante, Smythe (1970) e Jackson (1981) também observaram que a dispersão de sementes grandes seria mais concentrada no decorrer do ano, fato que pode explicar os picos de biomassa de sementes observados na porção do baixo no início do período chuvoso.

Os valores de riqueza, diversidade e equabilidade de morfoespécies de sementes registrados nas três porções de floresta confirmaram a elevada diversidade e reduzida dominância ecológica da chuva de sementes dessa comunidade, em comparação com estudos similares (BRAGA et al., 2008).

Os valores da riqueza e diversidade de morfoespécies de sementes foram, entretanto, inferiores àqueles registrados por Miguel e Marimon (2008), um ano antes da realização deste estudo, quando amostraram árvores, arbustos, palmeiras e lianas nas mesmas porções de floresta. A menor riqueza e diversidade de morfoespécies de sementes em relação à riqueza e diversidade de espécies lenhosas registradas nas mesmas porções de floresta são aspectos essenciais a serem considerados na conservação dessa comunidade. Nesse caso, pode-se supor que os impactos sofridos no passado, como uma queimada em 2001 (MIGUEL; MARIMON, 2008), tenham alterado a capacidade reprodutiva de algumas espécies, visto que a diversidade de sementes coletadas no decorrer de um ano (2007-2008) foi inferior à de espécies lenhosas registradas no ano anterior (2006). Considerando que a referida floresta se encontra localizada em uma unidade de conservação, medidas mitigadoras são indispensáveis para garantir a integridade dessa fitocenose e evitar que o desenvolvimento das espécies seja comprometido.
Este estudo poderá ser utilizado como indicador que permitirá a avaliação de relações de causa e efeito sobre a reprodução das espécies, sendo possível fazer previsões sobre o comportamento, no médio e no longo prazo, quanto à sustentabilidade do ecossistema e à capacidade de regeneração dessa floresta de galeria.

\section{CONCLUSÕES}

O elevado número de morfoespécies e a densidade de sementes sem estruturas de voo na floresta do Córrego Bacaba reafirmam seu importante papel na disponibilização de alimentos para a fauna silvestre.

A proximidade geográfica das porções de floresta estudadas contribui para a similaridade no padrão de dispersão de sementes.

A menor riqueza e diversidade de morfoespécies de sementes em relação à riqueza e diversidade de espécies de plantas indicam que os impactos sofridos por essa floresta no passado alteraram a capacidade reprodutiva de algumas espécies.

\section{AGRADECIMENTOS}

À CAPES, pela bolsa concedida à primeira autora; à UNEMAT (FIDPEX) e ao CNPq (PELD, Proc. 558069/ 2009-6), pelo apoio financeiro durante a execução deste trabalho; ao biólogo Leandro Maracahipes e às discentes Bianca Oliveira e Lucélia Santos da Silva, pela contribuição na coleta de dados no campo e seleção/ separação das sementes; e aos três revisores anônimos, pelas valiosas sugestões.

\section{REFERÊNCIAS}

ALVAREZ-BUYLLA, E. R.; MARTÍNEZ-RAMOS, $M$. Seed bank versus seed rain in the regeneration of a tropical pioneer tree. Oecologia, v.84, n.3, p.314-325, 1990.

\footnotetext{
ARAÚJO, R. S. Chuva de sementes em

três modelos de revegetação de

áreas degradadas, na Reserva

Biológica de Poço das Antas, Silva

Jardim, RJ. 2002. 92f. Dissertação

(Mestrado em Ciências Ambientais e

Florestais) - Universidade Federal Rural do

Rio de Janeiro, Rio de Janeiro, 2002.
}

Revista Árvore, Viçosa-MG, v.36, n.2, p.311-320, 2012 
ARAÚJO, M. M. et al. Caracterização da chuva de sementes, banco de sementes do solo e banco de plântulas em floresta estacional decidual ripária, Cachoeira do Sul, RS, Brasil. Scientia

Forestalis, n.66, p.128-141, 2004.

BRAGA, A. J. T. et al. Composição do banco de sementes de uma floresta semidecidual secundária considerando o seu potencial de uso para recuperação ambiental. Revista Árvore, v.32, n.6, p.1089-1098, 2008.

CAMPOS, E. P. et al. Chuva de sementes em floresta estacional semidecidual em Viçosa, MG, Brasil. Acta Botanica Brasilica, v.23, n.2, p.451-458, 2009.

FELFILI, J. M. et al. Flora fanerogâmica das matas de galeria e ciliares do Brasil central. In: RIBEIRO, J. F.; FONSECA, C. E. L.; SOUSA-SILVA, J. C. (Org.). Cerrado: caracterização e recuperação de matas de galeria. Planaltina: Embrapa, 2001. p.195-263.

FOSTER, S. A.; JANSON, C. H. The relationship between seed size and establishment conditions in tropical woody plants. Ecology, v.66, n.3, p.773-780, 1985.

GARCIA, E. Chuva de sementes em um fragmento de floresta estacional semidecídua em Campinas (SP). 2007. 53f. Dissertação (Mestrado em Ecologia) Universidade Estadual de Campinas, Campinas, 2007.

GROMBONE-GUARATINI, M.T. Dinâmica de uma floresta estacional semidecidual: o banco, a chuva de sementes e o estrato de regeneração. 1999. 150f. Tese (Doutorado em Ecologia) - Universidade Estadual de Campinas, Campinas, 1999.

GROMBONE-GUARATINI, M. T.; RODRIGUES, R. $\mathrm{R}$. Seed bank and seed rain in a seasonal semideciduous forest in south-eastern Brazil.

Journal of Tropical Ecology, v.18, n.5, p.59-774, 2002.

HOLL, K. D. Factors limiting tropical rain forest regeneration in abandoned pasture: seed rain, seed germination, microclimate, and soil. Biotropica, v.31, n.2, p.229-242, 1999.
INSTITUTO BRASILEIRO DE GEOGRAFIA E ESTATÍSTICA - IBGE. Árvores do Brasil Central. Rio de Janeiro: 2002. 417p.

JACKSON, J. F. Seed size as a correlate of temporal and spatial patterns of seed fall in a neotropical forest. Biotropica, v.13, n.2, p.121-130, 1981.

LIEBSCH, D.; ACRA, L. A. Síndromes de dispersão de diásporos de um fragmento de floresta ombrófila mista em Tijucas do Sul, PR. Curitiba. Revista Acadêmica, v.5, n.2, p.167-175, 2007.

LOISELLE, B. A.; RIBBENS, E.; VARGAS, O. Spatial and temporal variation of seed rain in a Tropical Lowland Wet Forest. Biotropica, v.28, n.1, p.82-95, 1996.

\section{LUDWIG, J. A.; REYNOLDS, J. E. Statistical} ecology - a primer on methods and computing. New York: J. Wiley \& Sons, 1988. 337p.

\section{MAGURRAN, A. E. Ecological diversity} and its measurement. London: Croom Helm., 1988. 179p.

MARIMON, B. S.; FELFILI, J. M. Chuva de sementes em uma floresta monodominante de Brosimum rubescens Taub. e em uma floresta mista adjacente no Vale do Araguaia, MT, Brasil. Acta Botanica Brasilica, v.20, n.2, p.423-432, 2006.

MARIMON, B. S. et al. Distribuição de circunferências e alturas em três porções da mata de galeria do Córrego Bacaba, Nova Xavantina-MT. Revista Árvore, v.25, n.3, p.335-343, 2001.

MARIMON, B. S.; FELFILI, J. M.; LIMA, E. S. Floristcs and phytosociology of the gallery forest of the Bacaba Stream, Nova Xavantina, Mato Grosso, Brazil. Edinburgh Journal of Botany, v.59, n.2, p.303-318, 2002.

MARIMON, B. S. et al. Padrões de distribuição de espécies na mata de galeria do Córrego Bacaba, Nova Xavantina, MT. Boletim do Herbário Ezechias Paulo Heringer, v.12, n.1, p.84-100, 2003. 
MARIMON, B. S. et al. Environmental determinants for natural regeneration of gallery forest at the Cerrado/Amazonia boundaries in Brazil. Acta Amazonica, v.40, n.1, p.107-118, 2010.

MARquES, M. C. M. Dinâmica da dispersão de sementes e regeneração de plantas da planície litorânea da Ilha do Mel, Paraná. 2002. 159f. Tese (Doutorado em Ciências Biológicas) Universidade Estadual de Campinas, Campinas, 2002.

MARTÍNEZ-RAMOS, M.; SOTO-CASTRO, A. Seed rain and advanced regeneration in a tropical rain forest. Vegetatio, v.107/108, n.1, p.299-318, 1993.

MARTINI, M. Z. Estrutura e composição da vegetação e chuva de sementes em sub-bosque, clareiras naturais e área perturbada por fogo em floresta tropical no sul da Bahia. 2002. 138f. Tese (Doutorado em Ecologia) - Universidade Estadual de Campinas, Campinas, 2002.

MARTINS, M.; ZANZINI, A. C. S.; SANTIAGO, W. T. V. Síndromes de dispersão em formações florestais do Bioma Cerrado no estado do Tocantins. Revista Brasileira de Biociências, v.5, n.1, p.807-809, 2007.

MELO, F. P. L.; DIRZO, R.; TABARELLI, M. Biased seed rain in forest edges: evidence from the Brazilian Atlantic Forest. Biological Conservation, v.132, n.1, p.50-60, 2006.

MIGUEL, A.; MARIMON, B. S. Mudanças na composição florística e na diversidade de espécies em três áreas da mata de galeria do Córrego Bacaba (Nova Xavantina, MT). In:

SANTOS, J. E.; GALBIATI, C. (Org.). Gestão e educação ambiental - água, biodiversidade e cultura. São Carlos: RIMA, 2008. p.93-116.

MORELLATO, P. C. As estações do ano na floresta. In: LEITÃO-FILHO, H. F.; MORELLATO, L. P. (Org.). Ecologia e preservação de uma floresta tropical urbana Reserva de Santa Genebra. Campinas: UNICAMP, 1995. p.37-41.
OLIVEIRA-FILHO, A. T. Composição florística e estrutura comunitária da floresta de galeria do Córrego da Paciência, Cuiabá, MT. Acta Botanica Brasilica, v.3, n.1, p.91-111, 1989.

PENHALBER, E. F.; MANTOVANI, W. Floração e chuva de sementes em mata secundária em São Paulo, SP. Revista Brasileira de Botânica, v.20, n.2, p.205-220, 1997.

PHILLIPS, O. L. The changing ecology of tropical forests. Biodiversity and Conservation, v.6, n.2, p.291-311, 1997.

PINTO, L. V. A. et al. Distribuição de espécies arbóreo-arbustivas ao longo do gradiente de umidade do solo de nascentes pontuais da bacia hidrográfica do Ribeirão Santa Cruz, Lavras, MG. Cerne, v.11, n.3, p.294-305, 2005.

PIVELLO, V. R. et al. Chuva de sementes em fragmentos de floresta atlântica, São Paulo, SP, Brasil, sob diferentes situações de conectividade, estrutura florestal e proximidade da borda. Acta Botanica Brasilica, v.20, n.4, p.845-859, 2006.

POTT, A.; POTT, V. J. Plantas do Pantanal. Brasília: EMBRAPA-CPAP/SPI, 1994. 320p.

RIBEIRO, J. F.; WALTER, B. M. T. As principais fitofisionomias do Bioma Cerrado. In: SANO, S. M.; ALMEIDA, S. P.; RIBEIRO, J. F. (Org.). Cerrado: ecologia e flora. Brasília: Embrapa Cerrados, 2008. p.153-212.

SCHIAVINI, I.; RESENDE, J. C. F.; AQUINO, F. G. Dinâmica de populações de espécies arbóreas em mata de galeria e mata mesófila na margem do Ribeirão Panga, MG. In: RIBEIRO, J. F.;

FONSECA, C. E. L.; SOUSA-SILVA, J. C. (Org.). Cerrado: caracterização e recuperação de Matas de Galeria. Planaltina: Embrapa, 2001. p.267-299.

SILVA, C. R. Fitossociologia e avaliação da chuva de sementes em uma área de floresta alta de restinga, em ilha comprida, São Paulo. 2006. 95f. Dissertação (Mestrado em Biodiversidade Vegetal e Meio Ambiente) - Instituto de Botânica, São Paulo, 2006.

SMYTHE, N. Relationships between fruiting seasons and seed dispersal methods in a neotropical forest. The American Naturalist, v.104, n.935, p.25-35, 1970.

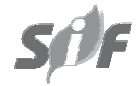

Revista Árvore, Viçosa-MG, v.36, n.2, p.311-320, 2012 
STATISTICALPACKAGEFORTHESOCIALSCIENCESSPSS. SYSTAT 7.0 for Windows. Chicago: 1997.

SWAINE, M. D.; WHITMORE, T. C. On the

definition of ecological species groups in tropical rain forests. Vegetatio, v.75, n.1-2, p.81-86, 1988.
VAN DER PIJL, L. Principles of dispersal in higher plants. New York: Springer-Verlag, 1972. 214p.

ZAR, J. H. Bioestatistical analysis. 4. ed. New Jersey: Prentice Hall, 1999. 663p. 